\title{
Mujeres en vilo: Género y Guerra fría en América Latina
}

\author{
Dora Barrancos ${ }^{(*)}$
}

\begin{abstract}
Resumen
Es una tarea particularmente ardua abordar el fenómeno de la denominada Guerra fría, desde una perspectiva que incluya especialmente a las mujeres, tan afectadas como los varones por los hostigamientos y las persecuciones, toda vez que han sido estos los actores casi exclusivos de la historiografía especializada y no sólo en América Latina. Este artículo analiza dos sociedades en dos momentos cronológicos diferenciados en el marco contextual de la Guerra fría que propendió a la desestabilización de gobiernos democráticos dando curso a la instauración de dictaduras institucionales en la región. En esos escenarios se rescata el rol de mujeres tanto en clave individual y colectiva. En el caso de Guatemala se focaliza en la trayectoria de María Cristina Vilanova, esposa del Presidente Arbenz. En el segundo caso, Brasil, se introduce un movimiento femenino en el marco de las luchas contra la dictadura impuesta en 1964, el Movimento Femenino pela Anistía (MFPA) que vio la luz en 1975.
\end{abstract}

Palabras clave: Guerra Fría; Dictadura; Mujeres; Guatemala; Brasil.

Women on the Brink: Gender and the Cold War in Latin America

\begin{abstract}
It is a particularly arduous task to approach the phenomenon of the so-called Cold War from a perspective that includes women, who are just as affected as men by harassment and persecution, given that they have been the almost exclusive actors in specialised historiography, and not only in Latin America. This article analyses two societies in two different chronological moments in the contextual framework of the Cold War, which led to the destabilisation of democratic governments and the establishment of institutional dictatorships in the region. In these scenarios, the role of women is highlighted both individually and collectively. In the case of Guatemala, the focus is on the career of Maria Cristina Vilanova, wife of President Arbenz. In the second case, Brazil, a women's movement is introduced within the framework of the struggles against the dictatorship imposed in 1964, the Movimento Femenino pela Anistia (MFPA), which emerged in 1975.
\end{abstract}

Key Words: Cold War; Dictatorship; Women; Guatemala; Brazil.

\footnotetext{
(*) Universidad Nacional de Buenos Aires (UBA), Universidad Nacional de Quilmes (UNQ), Consejo Nacional de Investigaciones Científicas y Técnicas (CONICET). Argentina. Mail: barrancosconicet@gmail.com ORCID: https://orcid.org/0000-0003-1415$\underline{4310}$.
} 


\section{Mujeres en vilo: Género y Guerra fría en América Latina}

\section{Introducción}

Es una tarea particularmente ardua abordar el fenómeno de la denominada Guerra fría -que a menudo adquirió formas de guerra caliente abierta, pero que nunca dejó de ser una cruzada cultural-, ${ }^{1}$ desde una perspectiva que incluya especialmente a las mujeres, tan afectadas como los varones por los hostigamientos y las persecuciones, toda vez que han sido estos los actores casi exclusivos de la historiografía especializada y no sólo en América Latina. En efecto se dispone de una vasta literatura sobre las diversas formas que adquirió la Guerra fría y que da cuenta de los estragos producidos por esta particular configuración de la hostilidad de Estados Unidos de América - en estrecha relación con los países aliados- contra el pensamiento y la acción de las "izquierdas", y aun contra fórmulas liberales críticas, en el ciclo que abrió el fin de la Segunda guerra. Debe recordarse que la influencia norteamericana había ido aumentando progresivamente en las primeras décadas del siglo pasado y que esa influencia a menudo supuso acciones directas en diferentes países de la región, sobre todo a raíz de la crisis del '29-'30, cooperando así con el surgimiento de dictaduras anteriores a la Guerra fría. Pero fue sin duda a la finalización de la segunda contienda mundial, a mediados de los '40, cuando los Estados Unidos desplegaron diversas metodologías para que la región latinoamericana se subordinara política y económicamente a sus orientaciones. Este país pasó a dominar la escena con toda suerte de manifestaciones anticomunistas, con la puesta a raya de movimientos que pudieran significar el peligro de una posible instalación de regímenes de izquierda.

Haré un rápido repaso introductorio de las circunstancias que sirvieron para justificar el fenómeno en un periodo que recorre desde 1945 hasta la extinción de la URSS a raíz de los acontecimientos de 1989. Fueron casi cincuenta años en que la "lucha anticomunista" ciertamente el objetivo principal de la contienda "fría"-, se desarrolló en muy diversas latitudes. Es bien sabido que el temor de que la Unión Soviética extendiera sus tentáculos a raíz del enorme malestar engendrado por la guerra, y que se establecieran regímenes comunistas en buena parte del orbe, condujo a la una manifiesta hostilidad por parte de los gobiernos norteamericanos para impedir que tales circunstancias se concretaran. Estados Unidos desplegó estrategias llamadas de "contención” en diversos lugares, tales como la ayuda brindada a Grecia y a Turquía a fin de evitar que pudieran emprender cursos radicalizados afinados con la Unión Soviética. El propio Plan Marshall, destinado a la reconstrucción alemana, debe ser visto dentro

${ }^{1}$ Bozza (1996) sostiene que "la sistematicidad con que se planificaron sus acciones, la magnitud de los recursos materiales y humanos insumidos, la perdurabilidad de sus programas y el dilatado ámbito internacional en el que se desplegaron confirman la pertinencia del término guerra fría cultural" (Bozza, 1996: 50). El autor se basa especialmente en los análisis de France Stonor Saunders (1999). 


\section{Dora Barrancos}

de esta política general para morigerar las crisis y prevenir movimientos radicalizados que pudieran inclinar la balanza hacia el comunismo.

Pero adentrémonos en el paisaje oscuro de la Guerra fría en América Latina. El viraje sustantivo con referencia a la región y las preocupaciones norteamericanas con la probable inestabilidad que pudiera llevar a regímenes de izquierda, de acuerdo con Morgenfeld (2010), no se suscitaron de modo enérgico sino hasta la década 1950, y se exhibieron en forma contundente en la Décima Conferencia de la OEA que tuvo lugar en Caracas en marzo de 1954. No es posible, en los límites de este trabajo, dar cuenta del arco de hostigamientos sufridos en los países latinoamericanos a raíz del temor al surgimiento de regímenes socialistas con base en una perspectiva generizada, aunque hay un importante número de investigaciones en curso tal como se pone en evidencia en este libro. ${ }^{2}$ Centraré el análisis en dos sociedades y en dos momentos cronológicos diferenciados en el marco contextual de la Guerra fría que, de todos modos, propendió a la desestabilización de gobiernos democráticos dando curso a la instauración de dictaduras institucionales en la región.

\section{Una pareja en la mira: Juan Jacobo Arbenzy María Cristina Vilanova de Arbenz}

Desearía incursionar inicialmente en los acontecimientos de Guatemala, deteniéndome en la ascensión y destitución del Presidente Juan Jacobo Arbenz, tal vez un hito en la historia de la Guerra fría y que revela la nueva atención que desplegaba EEUU hacia América Latina, en la mitad de los años 50. La historia personal de Arbenz exhibe una evolución hacia posiciones de izquierda en el transcurso de una Guatemala en la que dominaban los intereses norteamericanos a propósito de la regencia de la United Fruits Company, dedicada al comercio de frutas tropicales y que como es bien sabido señoreaba en toda la región caribeña. El poderoso emporio, que incluía una flota marítima, ejercía influencia directa en la política de los países centroamericanos desde fines del XIX y deben evocarse las represiones trágicas en Colombia y Costa Rica, y que en este país su célebre nombre fue "mamita yunai”. Miles de trabajadoras y trabajadores fueron ultimados a propósito de rebeliones a causa de la explotación -en buena medida se trataba de trabajo servil-, las pésimas condiciones de vida y los impedimentos para la sindicalización. En Guatemala la compañía había obtenido toda suerte de beneficios con la aquiescencia de los gobiernos, hasta que un nuevo golpe militar terminó con la presidencia -de muy breve tiempo- de Juan Federico Ponce Vaides en octubre de 1944. De la asonada participó

\footnotetext{
${ }^{2}$ Un importante antecedente ha sido el Workshop "Las comunistas iberoamericanas durante la política de frentes y la guerra fría", Grupo de Estudios de Sociología Histórica de América Latina (GESHAL)/Facultad de Ciencias Sociales/UBA, Buenos Aires, 22 de abril de 2016. Hay aportes significativos en Valobra y Yusta (en prensa).
} 
el joven militar Arbenz, quien provenía de una familia de clase media acomodada -su padre era suizo alemán y de profesión farmacéutico-, pero que finalmente afrontó serios problemas económicos al punto de perder el estatus social inicial. Fue enviado para formarse en la academia militar justamente por falta de recursos para costear otra carrera. Era inteligente y con una especial percepción de los problemas sociales que caracterizaban a Guatemala, percepción aguzada cuando, a raíz de los destinos que le asignaron, pudo ver de cerca el estado servil de los indígenas, las condiciones miserables de existencia y también las represiones que sufrían. La derrocada de Ponce Vaides dio lugar a la instalación de un triunvirato militar y uno de sus integrantes fue Arbenz quien exhibió las posiciones más avanzadas, y tal vez las más decididas, en la convocatoria a una nueva constitución que garantizara más derechos y que incluyera la ciudadanía de las mujeres.

No cabe duda de la influencia que ejercieron las esposas de los tres militares para avanzar en este último aspecto, aunque sobresale la posición de María Cristina Vilanova, la esposa de Arbenz de quien me ocuparé especialmente. Surgieron así, con el nuevo plexo normativo guatemalteco de 1945, nuevas formulaciones de derechos y garantías de terminar con el trabajo forzado -generalmente impuesto a los campesinos díscolos y también a detenidos-, la declaración de la ciudadanía de las mujeres y el sufragio de estas, aunque se limitó a las alfabetizadas. En las elecciones que siguieron fue electo Juan José Arévalo y su gobierno estuvo gravemente tensionado por las diferencias entre los miembros del gabinete posicionados entre la derecha -en las que era fuerte el mayor Francisco Arana, quien intentó la salida de Arévalo y que en un confuso episodio resultaría asesinado- y un sector más a la izquierda, en la que destacaba la figura principal de Arbenz. Hubo una reorganización del ejército de modo a impedir que el grupo del generalato resultara el factotum de la gobernanza, mientras fungía como Ministro de Defensa el propio Arbenz. Se había opuesto a medidas francamente reaccionarias como la deportación de un conjunto de obreros a los que se sindicaba de comunistas.

Hacia 1947 Arbenz estaba más inclinado a pensar que las injusticias y el atraso de Guatemala sólo podrían resolverse mediante medidas económicas y sociales radicales, y percibía con claridad los estragos de las compañías norteamericanas y no sólo en la economía pues pudo distinguir los niveles de explotación y de servilismo al que estaban sometidas las poblaciones indígenas a menudo expuestas a hambrunas, cuando no a castigos inenarrables. Fue en esa decidida transición de su pensamiento que tomó contacto con José Manuel Fortuny, destacado líder de la izquierda guatemalteca -aunque se ha sostenido que fue este quien deseó conocerlo a propósito de sus díscolas posiciones en el gabinete-. Se trató de un vínculo entrañable y de enorme significado pues Arbenz pudo avizorar con mayor nitidez las concepciones 


\section{Dora Barrancos}

antiimperialistas y la necesidad de transformación social radical de las sociedades latinoamericanas, en las que se imponía, de modo inexcusable, la reforma agraria. En 1951 fue candidato presidencial por el Partido Guatemalteco del Trabajo acompañado en la fórmula por Fortuny y se abrió entonces un cauce para las reformas.

En 1939, Juan Jacobo Arbenz había contraído matrimonio con María Cristina Vilanova, a quien ya he introducido y que jugaría un papel singular en su vida. La joven pertenecía a una familia de clase alta de El Salvador, pues su padre, José Antonio Vilanova de Kreitz, era propietario de cafetales, conservador y pronunciadamente anticomunista. En 1932 se desarrolló en ese país un acontecimiento luctuoso con la masacre de algunos centenares de aborígenes, acontecimiento en el que estuvo implicado. María Cristina, que había recibido una educación bastante esmerada para los cánones de la época, con conocimientos de varios idiomas, tenía un temperamento que la puso en discordancia con las ideas de su padre y tempranamente manifestó preocupación por la situación de las clases pobres. Conoció a Arbenz en ocasión de una visita a Guatemala y de acuerdo a su propio testimonio fue un flechazo más allá de las evidencias de las diferencias de cultura entre ambos, tal como narra en su libro Mi esposo, el Presidente Arbenz. ${ }^{3}$ Pero coincidían en muchos aspectos que concernían sobre todo a la común visión acerca de las injusticias sociales, y el vínculo fortaleció las posiciones hacia una mayor radicalidad.

No hay dudas de que María era una compañera en el ideario de las reformas, y al momento de la asunción de Arbenz fue determinada en las acciones de asistencia social, con mayor énfasis que la típica figuración caritativa que solían ejercer las primeras damas en Latinoamérica. No pocas veces se ha comparado la tarea emprendedora de María -tal como familiarmente era designadacon la propia de Eva Perón, la notable Evita para los sectores desposeídos de Argentina. No hay duda de que la proyección del peronismo había tocado a la pareja presidencial guatemalteca, y que un conjunto de disposiciones gubernamentales para auxiliar a los sectores menos favorecidos, encuentra su matriz en la experiencia argentina. De hecho, María pudo visitar varias veces la Argentina durante el peronismo, y como había ocurrió con la Fundación Eva Perón, se dedicó a atender a las poblaciones pobres, en particular a las mujeres y a los niños. Solía estar presente en la mayoría de los actos de gobierno acompañando a su marido. Se decía que lo inspiraba en las principales gestas, que oficiaba de virtual "Primer Ministro", pero lo cierto es que apoyaba sus políticas, la acción contra la United Fruits, cercenando sus tentáculos a raíz de la confiscación de sus tierras ociosas (poco más del 60\% de la tierra que disponía el emporio) - parte de la reforma agraria iniciada en junio de $1952-,{ }^{4}$ y la iniciación de la obra hidroeléctrica que terminaría con el monopolio energético de los EEUU. Pero también hubo importantes reformas educativas en Guatemala y emprendimientos culturales públicos, como el

\footnotetext{
${ }^{3}$ (Vilanova de Arbenz, 2003).

${ }^{4}$ (Anahté, 1996).
} 
desarrollo que cobró el Ballet Guatemala, ${ }^{5}$ transformaciones que no eran ajenas a las preocupaciones de la esposa de Arbenz. María era recelada por su protagonismo en las reformas que encaraba el régimen suscitando no pocos enemigos, pero el gobierno norteamericano fue decisivo en la saga que llevaría a su derrocada en 1954, especialmente por la acción emprendida por la CIA.

El proceso que culminó con la forzosa renuncia de Arbenz estuvo signado por toda clase de denuncias, por una insidiosa y sistemática propaganda con acusaciones de que se trataba de un gobierno comunista, un peligro para la región que se encendía en el contexto de la Guerra fría. La insurgencia fue planeada en detalle por la CIA y tuvo un personero directo, John Peurifoy, designado embajador en Guatemala por el Presidente Eisenhower, a donde llegó en noviembre de 1953 después de una gestión en Grecia. La pendencia con los intereses norteamericanos, acicateada por la exigencia de una indemnización desmedida a la United Fruits, escaló fuertemente. La defensa de esos intereses se identificaba con el fortalecimiento de la lucha anticomunista en la región. A la sazón se habían incrementado los enemigos del gobierno que iban desde las clases terratenientes hasta segmentos descontentos de las capas medias -una buena parte del estudiantado era contraria a Arbenz-, sin que pueda pasarse por alto el papel opositor de la Iglesia Católica, cuyos prelados no sólo eran manifiestamente anticomunistas, sino que a menudo encendían el púlpito con ataques directos a los Arbenz.

El golpe se inició el 18 de junio de 1954 con grupos armados que ingresaron desde Honduras al mando del Coronel Carlos Castillo Armas, que estaba exiliado en ese país. A esos contingentes se unieron saboteadores directamente contratados por la CIA, y aunque parecían evidentes las dificultades para que esta asonada fuera exitosa, resulto decisivo el plegamiento de una parte del ejército originando la dramática renuncia de Arbenz, tal vez una de las más enigmáticas que la historiografía ha deseado desentrañar. María nos ha dejado su interpretación cuando narra que Arbenz cabildeó largo con su entorno y especialmente con Fortuny, y que este le aseguraba que no podrían de ningún modo hacer frente a una invasión directa norteamericana. Pero también, insinúa que Arbenz evitó la resistencia armada, tal vez temeroso de que fuera insostenible y que a la postre hubiera muchos más perjuicios que los que originaría su alejamiento del poder. Solía excederse en el consumo de alcohol, problema que lo había llevado a consultas médicas. No solía manifestarse de manera locuaz pues era más bien contenido, y afectivamente estaba muy aferrado a María. Es muy probable que el dilema entre resistir o renunciar, y la decisión finalmente tomada hicieron mella en una personalidad que de cualquier modo estaba lejos de la

${ }^{5}$ El Ballet de Guatemala fue una notable experiencia cultural que se extendió entre 1949 y 1954. A su frente estuvo el maestro ruso Leonide Katchourowsky, acompañado por su esposa Marie Tchernova (que había sido primera bailarina de la Opera de Paris), y la profesora Marcelle Bonge. A la caída de Arbenz, se los acusó de comunistas, se extinguieron sus contrataciones y tuvieron que regresar a Europa. 


\section{Dora Barrancos}

completa desestructuración psicológica como hicieron correr los medios que le eran adversos, la obstinada propaganda anti Arbenz en que se empeñó el gobierno de los Estados Unidos.

No me detendré en las circunstancias humillantes que vivieron los derrocados, obligados en su mayoría a asilarse en embajadas, como fue el caso de la familia Arbenz -tenían tres hijos, dos mujeres $^{6}$ y un varón- y de la mayoría de los miembros del gabinete. Si el ex presidente fue objeto de una encarnizada campaña de desprestigio, con ataques personales y fórmulas detractoras que iban desde caracterizaciones de su comunismo -subrayando la peligrosidad de sus ideas que respondían de modo directo a los designios del Kremlin-, hasta las dificultades psicológicas responsables de su inveterada debilidad, de los cambios de carácter, a menudo de su ensimismamiento y de fases agudamente depresivas que lo aislaban por completo, no fueron menores los ataques a la impetuosa María. No dejaba de apreciarse su responsabilidad en las políticas trazadas y se divulgaba que sólo de manera convencional seguía fungiendo como la esposa del ex mandatario pues era una adúltera.

Es evidente el tenor interesado de esa propaganda que calaba hondo en las sociedades latinoamericanas, sobre todo entre los grupos sociales dominantes que veían en los trazos del presidente guatemalteco depuesto señales deplorables en muchos sentidos. Los Arbenz padecieron un exilio errático, generalmente tenso y por momentos muy doloroso, comenzando por los más de dos meses que estuvieron asilados en la Embajada de México, adonde llegaban los insultos de grupos que se convocaban al frente del edificio, a menudo nutrido de mujeres, que profería gritos contra "la guanaca", refiriéndose a María. ${ }^{7}$ Al inicio estuvieron en México, aunque pasaron por Canadá a recoger a su hija Arabella - quien años más tarde terminó suicidándose en Colombia-, y vivieron en Francia, Suiza, la Unión Soviética, Checoslovaquia, Uruguay, Cuba, y en las postrimerías, nuevamente regresaron a México, donde Arbenz pareció asentarse con mayor comodidad dada la cercanía con Guatemala, pues nunca desistió del deseo de incidir en su país. Fue allí donde falleció en enero de 1971. Costa Rica acogió a María y en su última etapa estuvo acompañada sólo por el hijo varón, pues también se suicidó la otra hija, Leonora, quien sufría serios problemas mentales y estuvo varias veces internada en clínicas especializadas.

Deseo destacar la persecución de que fue objeto María durante mucho tiempo, el ensañamiento dedicado por sus detractores como Carlos Manuel Pellecer, una figura insidiosa que comenzó con una identificación de izquierda, acompañante de los gobiernos de Arévalo y del propio Arbenz - quien lo había sumado a su grupo íntimo-, y que se tornó agente de la CIA, por cierto con mucha eficacia porque se desempeñó por algún tiempo como profesor en universidades soviéticas. Pellecer aparecía como amigo del ex presidente, mientras enviaba informes acerca de

\footnotetext{
${ }^{6}$ La mayor de las hijas, Arabella a la sazón se encontraba estudiando en Canadá.

${ }^{7}$ Declaraciones de María Cristina Vilanova a la revista Crónica- Año IX, 1996. http://cronica.ufm.edu/index.php/DOC487.pdf
} 
sus estados de ánimos y actividades a la CIA. La animosidad contra María lo llevó a explicar la renuncia de Arbenz por causa de su infidelidad, adjudicándole un amante cubano en el libro autobiográfico, Arbenz y yo, ${ }^{8}$ quien también la habría seguido en el exilio parisino y que de modo permanente los chantajeaba. El autor se atribuía un vínculo de enorme intimidad con Arbenz y fraguó hasta una suerte de confesión de este quien le habría confesado que no había podido resistir el embate psicológico de la desavenencia conyugal, aunque se había visto obligado a soportar el adulterio. Este aspecto de la supuesta inestabilidad emocional tuvo una retomada reciente, y con base sobre todo en la argumentación aportada por Pellecer -y también de otro espía, Howard Hunt, igualmente acérrimo enemigo de la causa arbenzista ${ }^{9}$ - como puede observarse en el trabajo de Cabrera Geserick (2009) quien explica la debacle de la renuncia de Arbenz a propósito del alejamiento sentimental de María.

García Ferreira (2009) ofrece datos más sólidos acerca de las falacias de Pellecer, y no sólo por los testimonios aportados por la propia María en las entrevistas que pudo hacerle en su exilio costarricense, y por la narrativa de su libro, sino por las interpretaciones que este autor realiza sobre la malla mucho más compleja del contexto guatemalteco de 1954 y de la encarnizada persecución que largamente sufrieron los esposos Arbenz por parte del Departamento de Estado norteamericano y su brazo, la CIA (García Ferreira, 2006). García Ferreira accedió al ejemplar de "Arbenz y yo" que María había obtenido algunos años más tarde de su publicación y que a manera de para texto se había empeñado en reescribir utilizando las márgenes, una especie de formulación antagónica de las aseveraciones de Pellecer, cuya expresión más acentuada podría ser la frase lanzada en la página 283 en la que escribe: "Qué fértil es la imaginación de un calumniador" (García Ferreira, 2006: 6).

Las tragedias personales, la muerte de sus dos hijas, las enormes dificultades para, a pesar de todo, permanecer al lado del hombre que amaba y admiraba -y con el que menudearon las desavenencias-, y a quien vio sufrir en momentos muy dolorosos, que bebía con desmesura y que se consumía en su deseo de repetir la era transformadora que había protagonizado en Guatemala, y que tal vez no se perdonó la mala decisión de haber renunciado, azuzaron la vida de María. Aunque se las arregló para no perder la entereza y soportar las injurias, no hay dudas de que se cuenta entre las víctimas de la Guerra fría.

\section{Mujeres y resistencia a la dictadura brasileña}

En 1964, momento en que he dejado la situación de Argentina, se produjo el golpe cívico militar que derrocó al gobierno de Joao Goulart en Brasil. Es imprescindible una introducción a la

\footnotetext{
${ }^{8}$ (Pellecer, 1997).
}

${ }^{9}$ (Hunt, 1975). 


\section{Dora Barrancos}

historia de este país para comprender lo ocurrido a partir de entonces. Brasil ofrece algunas singularidades con relación al resto de América Latina, tales como la pre existencia de una monarquía hasta fines del XIX, la tardía extinción de la esclavitud -en esto se parangona con Cuba-, la lenta formación de capas medias, la tardanza en constituir movimientos organizados de campesinos, la creación de partidos políticos de raigambre nacional recién a mediados de la década de 1940 (hasta entonces había partidos regionales), y el voto censitario según alfabetización que sólo fue removido en la última reforma constitucional de 1988. Otra característica de Brasil es que se encuentra entre los primeros países del continente que otorgó el voto a las mujeres, en 1932, aunque calificado. No puede dejar de mencionarse su singularidad, al menos con respecto a los países del cono sur, en materia de reclutamiento de los cuadros militares que mayoritariamente no provenían de los grupos sociales altos, se trataba de una incorporación matizada que daba lugar a jóvenes de los sectores bajos, por lo general habitantes del interior.

A diferencia de otras fuerzas armadas continentales, las brasileñas resultaban socialmente heterogéneas, de ahí que a menudo se sindicara a no pocos militares con ideas avanzadas. Las principales reformas sociales y políticas se realizaron con los gobiernos de Getulio Vargas, quien llegó al poder mediante el golpe de estado de 1930. El populismo que desarrolló tuvo incontestables visos autoritarios - piénsese en las restricciones civiles y políticas del llamado Estado Novo- y orientado a posturas de derecha. Basta destacar el acendrado anticomunismo del régimen que condujo a la extradición de Olga Benerio, ${ }^{10}$ en 1936, la joven judía alemana esposa del líder comunista Luis Carlos Prestes, ${ }^{11}$ acontecimiento ocurrido cuando este se hallaba en prisión a raíz de la frustrada asonada cívico-militar de izquierda de 1935 que puso en vilo a los sectores más conservadores.

Finalmente, debe subrayarse otro fenómeno del varguismo referido a que los sindicatos fueron constituidos como órganos del propio Estado, una asimilación que no se encuentra en otras experiencias populistas latinoamericanas. Cuando Vargas volvió al poder en un tercer mandato -mediante una inusitada alianza con el Partido Comunista que le brindó apoyo para impedir el retroceso de los derechos sociales-, se suicidó en agosto de 1954. La escena brasileña se dividía entre sectores progresistas, que impelían a reformas que redujeran el abismo entre las clases altas que dividían intereses entre la producción primaria -especialmente café- y el desarrollo industrial, entre cuyos obreros encontraba cierto predicamento el Partido Comunista, y también en el sector servicios, como en el segmento de los empleados bancarios. El país estaba social y económicamente fracturado entre las regiones con extrema pobreza, como ocurría en el

\footnotetext{
${ }^{10}$ En prisión nació su hija. Olga encontró la muerte en el campo de concentración nazi de Berenburg.

${ }^{11}$ Luis Carlos Prestes participó de la insurrección de los “tenientes”, a inicios de la década 1920, y luego constituyó un grupo insurgente que originó la larga marcha de la columna identificada con su nombre hasta su disolución en 1928, época en que ya se había identificado con el marxismo.
} 
amplísimo nordeste cuya población solía dejar la dureza del sertao, huyendo del hambre, para habitar los grandes centros urbanos, Sao Paulo y Rio de Janeiro. Hubo un interregno desarrollista con el gobierno de Jucelino Kubistchek, quien no estaba interesado en adherir a tesis marxistas pero que creía que era necesario horadar las profundas diferencias sociales y culturales de Brasil. Su Vicepresidente fue Joao Goulart -quien había ocupado la cartera de Trabajo durante el último gobierno de Vargas- y ya había acentuado sus preocupaciones con los sectores trabajadores y campesinos. Eran especialmente algunos grupos de clase media, profesionales e intelectuales de las grandes ciudades quienes solían manifestar la perspectiva más radicalizada de cambio.

Más adelante fue electo Janio Quadros, cuyo vicepresidente también fue Goulart, y por razones no bien desentrañadas -se ha aludido a problemas de personalidad-, Quadros renunció en agosto de 1961, y fue entonces que forcejearon sin tapujos los intereses ligados a las clases dominantes, apoyadas por el Departamento de Estado, a través de diversas operaciones. Se temía que la instalación de Goulart significase un giro que condujera al comunismo, por lo que se condicionó fuertemente su continuidad mediante un pacto de gobernanza en el que esta quedaba a cargo del Parlamento, hasta que sobrevivo un plebiscito popular que revocó esa disposición. ${ }^{12}$ Entre las fuerzas políticas que lo acompañaban se situaba en primer lugar el Partido Trabalhista do Brasil (PTB) en el que se destacaba la dirigencia del cuñado de Goulart, Lionel Brizola, a la sazón gobernador de Río Grande do Sul. No puede pasarse por alto la acción organizada de la Ligas Agrarias, especialmente en el nordeste bajo el liderazgo Francisco Julião, ya que se trataba de un amplio despertar de la conciencia de los campesinos, a merced de la explotación de los dueños de los latifundios.

En 1959, se había creado Instituto Brasileño de Acción Democrática (IBAD) y en 1961 el Instituto de Pesquisas e Estudos Sociais (IPÊS) y ambos organismos, que incluían también a militares, fueron fundamentales para que la CIA dispusieran de medios porosos para su accionar (Dreiffus, 1981; Fico, 2008; Ramírez, 2012). El IPÊS, según Ramírez:

"había producido varios filmes de corta duración de naturaleza ideológica en los que se alababa la iniciativa empresarial privada, los Estados Unidos y las Fuerzas Armadas a la par que se mostraba cómo el gobierno deterioraba esas instituciones e incentivaba el comunismo. Esos cortos eran exhibidos en los intervalos de filmes que se proyectaban para grupos específicos en espacios públicos como plazas de barriadas populares y zonas rurales o asociaciones y casas de estudios" (Ramírez, 2012: 263)

\footnotetext{
${ }^{12}$ Goulart tuvo ministros muy destacados en las ciencias sociales, como Celso Furtado a cargo de Economía y Darcy Ribeiro, en la cartera de Educación.
} 


\title{
Dora Barrancos
}

La agitación contra el gobierno fue en aumento, acicateada por las Marchas da Família com Deus pela Liberdade en Sao Paulo en la que participaban varios miles de manifestantes, especialmente mujeres de los sectores medios, con alegatos acerca de una inminente caída en el comunismo que acabaría con los valores familiares y que arrasaría la propiedad privada. El gobierno pudo reaccionar con un histórico acto que reunió también a miles de manifestantes, en la Central do Brasil, el 13 de marzo de 1964. En él, Goulart anunció una serie de reformas, entre ellas la agraria y urbana, en un clima de euforia. Estaba acompañado por su esposa Maria Thereza, a la sazón, una joven de 21 años. Aquel acto aceleró la asonada del 1 de abril cuando las fuerzas armadas acompañadas por segmentos entre los que descollaban los grupos empresarios, depusieron a Goulart quien salió hacia el exilio en Uruguay. María Thereza pudo confesar cincuenta años más tarde:

\begin{abstract}
"Até hoje, 50 anos depois eu me questiono para conseguir entender o porquê daqueles momentos tão assustadores que de repente mudaram o rumo de nossas vidas, de nossa pátria e de nosso povo. As mudanças foram infinitas. Perdi pessoas que eu amava sem poder dizer adeus.Perdi amigos, perdi meu lar e perdi minha pátria. Fiquei sem meus sonhos vivendo uma realidade de incertezas e desafetos. Tive medo sim e pensei que aqueles momentos eram de uma perseguição coletiva que acabaria envolvendo nosso futuro. Esse medo tornou-se um grande inimigo capaz de me confundir entre o ódio e o perdão". ${ }^{13}$
\end{abstract}

Entre los enemigos del régimen se habían situado varios grupos femeninos. De acuerdo a Ramírez (2012: 263) “el IPES costeaba, organizaba y orientaba políticamente a las tres organizaciones femeninas más importantes, a saber, la Campanha da Mulher pela Democracia (CAMDE), de Rio de Janeiro; la Uniao Civica Femenina (UCF) y la Campanha pela Educaçao Civica (CEC), así como una decena de otras entidades en particular Minas Gerais, Rio Grande do Sul y Pernambuco".

El golpe de estado de Brasil ha sido tomado como el inaugural en una suerte de segundo momento de los golpes institucionales - a los que siguieron Chile, Uruguay y Argentina

\footnotetext{
13 "Hasta hoy, 50 años después, me cuestiono para entender el porqué de aquellos momentos tan asustadores que de repente mudaron el rumbo de nuestras vidas, de nuestra patria, de nuestro pueblo. Los cambios fueron infinitos. Perdí personas que amaba sin poder decir adiós. Perdí mi hogar y mi patria. Quedé con mis sueños viviendo una realidad de incertezas y desafectos. Sí, tuve miedo y pensé que aquellos momentos eran de una persecución colectiva que acabaría envolviendo a nuestro futuro. Ese miedo se tornó un gran enemigo, capaz de confundirme entre el odio y el perdón" (traducción propia). Entrevista a Maria Thereza Goulart, "Lembranças de '64"- Instituto Joao Goulart- 15 de marzo de 2014, disponible en http://www.institutojoaogoulart.org.br/noticia.php?id=10717\&back=1 Joao Goulart murió en diciembre de 1976, en Mercedes (Corrientes, Argentina). Se estaba en plena dictadura y se conjetura, con bastante asidero, que fue asesinado por agentes de la Operación Cóndor.
} 
"Mujeres en vilo: Género y Guerra fría en América Latina"

(Ansaldi y Giordano, 2012) - y tal vez como una fase intermedia de la Guerra fría. No hay dudas de, que en Brasil fueron actores fundamentales las agencias norteamericanas pues se temía que ese país, de dimensiones continentales y tan gravitantes, cayera en el comunismo. Lo cierto es que la ruptura democrática de Brasil tuvo dos fases, una primera en la que las fuerzas golpistas moderaron un tanto la acción represiva 1964-1968, y una segunda fase en la que se mostró todo el calibre autoritario bajo el gobierno del General Artur da Costa e Silva en la que efectivamente se suspendieron las garantías constitucionales. Habían surgido varios focos de resistencia guerrillera, invariablemente integrados por mujeres y el arco contemplaba formaciones marxistas y también cristianas. Muchas eran de extracción media -y no pocas pertenecían a familias pudientes-, en su mayoría estudiantes o profesionales muy jóvenes como era el caso de Maria Lygia Quartim de Moraes, que acorralada por las circunstancias debió salir al exilio. Brasil fue el primer productor de exilios masivos en el cono sur, y muchos fugitivos escogieron Chile debido al socialismo imperante bajo la presidencia de Salvador Allende. A su dramática caída, debieron salir refugiados a países europeos.

Si para los varones fue difícil esta adaptación, a menudo cruzada por la desesperanza, para las mujeres la circunstancia del exilio fue severísima. Un testimoniante (G.R) me narró, hacia 1980, el caso de una joven exiliada en Ginebra que no había terminado estudios universitarios y que debido a su escasa calificación tenía que ocuparse de servicios personales, cuidaba a personas ancianas a las que atendía en todas sus necesidades. G.R. encontraba humillante esa tarea que deprimía a nuestra joven y le había indicado que lo mejor era optar por la prostitución en esa ciudad donde "los servicios sexuales eran los más caros del mundo". No escapa que es completamente difícil acertar en la disyuntiva, pero basta para asomar a la penumbrosa existencia de una joven exiliada en 1973. Hubo algunas circunstancias dramáticas, como ocurrió con otra joven que terminó suicidándose en Berlín.

La sociedad brasileña no dejó de agitarse, pero una de las primeras agencias organizadas para reclamar el cese de las persecuciones contra la militancia radicalizada y que solicitó la amnistía, provino de un grupo de mujeres. En efecto se debe inicialmente a un conjunto liderado por Therezinha de Godoy Zerbini, ${ }^{14}$ esposa de uno de los pocos generales que se mantuvo fiel a Joao Goulart, Euryale de Jesus Zerbini. Era mucho más joven que su marido, de profesión asistente social y había ejercido en un hospital cuando ocurrió el golpe, pero las mayores tribulaciones le ocurrieron en 1969 cuando cooperó para que se hiciera la primera reunión clandestina de la Uniao Nacional de Estudantes (UNE), y por esa razón fue detenida en febrero

14 Therezinha de Godoy Zerbini nació en Sao Paulo, en 1916 y murió en esta ciudad en 2015. 


\section{Dora Barrancos}

de 1970. La trasladaron a varios lugares y debió presenciar la tortura efectuada a Frei Tito. ${ }^{15}$ Estuvo ocho meses en prisión aplicándosele la Ley de Seguridad Nacional (1967) -una buena parte pasó en el presidio Tiradentes de Sao Paulo, en donde estaba también detenida quien sería Presidenta de Brasil, Dilma Roussef-.

En una entrevista que concedió a la periodista Elenonora de Lucena del periódico Folha de Sao Paulo (julio de 2012), Therezinha narró que sólo porque se mostró muy desafiante pudo sortear la tortura, ${ }^{16}$ y no ocultaba que tenía el apodo de "la burguesa" porque su familia le hacía llegar toda clase de asistencia. Sostuvo que nunca había sido comunista, pero no escapaba la simpatía que tenía por la Revolución cubana, y también dijo entonces que había asumido la causa de los pobres a raíz de la tuberculosis que contrajo siendo adolescente, ya que a raíz de su tratamiento había podido ver de cerca los cuadros de la pobreza.

En marzo de 1975, Therezinha y un grupo de compañeras creó el Movimento Femenino pela Amnistia (MFPA) y redactaron una suerte de presentación con el Manifesto da Mulher brasileira em favor da Anistía. El tono se deseaba no radicalizado pues contenía ideas moderadas como la necesidad de obtener la pacificación de las familias brasileñas y ganar la recomposición del pacto social (Fonteles Duarte, 2011: 245). El Manifesto señalaba que a través de la historia se había probado el espíritu solidario de la mujer y que esto había fortalecido las aspiraciones de amor y justicia. Como Fonteles Duarte interpreta, esa adecuación del lenguaje resulta una suspensión de la politicidad de la demanda, una inflexión de cualquier signo sobre cargado en orden a conseguir cierta aquiescencia de los militares, y también una mayor adhesión popular al propósito de obtener la amnistía para condenados y exiliados. En efecto, la actuación que se desplegaba en diversas ciudades, especialmente en las más importantes, tendía a reunir simpatizantes excluyendo las identificaciones con cualquier partido o fracción ideológica. "O discurso da pacificacao da familia, o enfrentamento mas brando com as autoridades militares -sostiene Fonteles Duarte-, e a constante negacao da vinculacao con a esquerda, sao características de um comportamento defensivo" (2011: 249). ${ }^{17}$

En junio de 1975, Therezinha asistió a la Conferencia Internacional de la Mujer de México y su participación fue decisiva para que se incorporara en el documento final el reclamo de "amnistía pata todos los presos políticos del mundo" (Fonteles Duarte, 2011: 246), pero no debe olvidarse que en esa Conferencia participaron muchas exiliadas y no sólo de América Latina. El MFPA no rechazaba por completo la inclusión de los varones, pero estos no tenían voto en las

\footnotetext{
15 Tito de Alencar Lima fue un fraile católico dominicano que adhirió a las ideas de izquierda. Fue preso en 1968, severamente torturado, deportado en 1971 a Chile y de allí se refugió finalmente en Francia. La experiencia de la tortura lo afectó psíquicamente. Tenía 28 años cuando todo indica que se suicidó en ese país en 1974.

${ }_{16}$ Folha de Sao Paulo. 11/07/2012, http://www1.folha.uol.com.br/poder/2012/07/1113275-minha-historia---therezinha-zerbini-aburguesona-que-foi-a-luta.shtml

17 "El discurso de la pacificación de la familia, el enfrentamiento más blando con las autoridades militares y la constante negativa de vinculaciones con la izquierda son características de un movimiento defensivo". Entrevista realizada para el conjunto de investigaciones Genero, feminismos e ditaduras no Cone sul, en Pedro, Scheibe Wolff, Veiga, 2022: 251 (traducción de la autora).
} 
reuniones. Therezinha elaboró una explicación acerca de aquel impedimento basada en un punto de vista que suena a feminista sosteniendo que:

"onde o homen vai, ele inibe. Você vai numa reuniao de operários, de estudantes, tem lá um grupinho de mulheres. Se tem homens eles inibem. Porque a mulher nao foi treinada, ela nao tem a velocidades mental, porque sempre foi o homem que mandou. Ele sempre foi o chefe e patrao" ${ }^{18}$.

Sin embargo, en esa entrevista, confesó que había tenido dificultades para lidiar con las mujeres, y de modo enfático sostuvo "sempre foi homen" -sin duda aludiendo a las características de su personalidad. Si por un lado la metodología del MFPA parecía responder a la necesidad de dar la plena voz a las mujeres otorgando un lugar central a sus acciones, por otro no se oculta que la propia Therezinha recelaba fuertemente que la inclusión de varones trajera contaminantes políticos partidarios. Las mujeres podrían ser un dique a esas inclinaciones y refiriéndose a integrantes de partidos al Partido Comunista do Brasil, PCdB y al Partido dos Trabalhadores (PT) -en verdad un lapsus porque este no existía entonces-, y aseguraba: "Eles querían abocanhar. Eu dizia: nao me venham fazer política dentro do Movimento, que nunca houve $(\ldots) " \cdot{ }^{19}$

El MFPA consiguió una buena cantidad de seguidoras, muy especialmente en Sao Paulo, Río de Janeiro y Belo Horizonte. En esta última ciudad, capital del Estado de Minas Gerais, la movilización fue muy importante, y se intentaba llegar a las mujeres de los sectores populares dado que la enorme mayoría de las integrantes eran de las clases acomodadas, se trataba de artistas, intelectuales, profesionales, estudiantes, empleadas calificadas. A veces las integrantes hacían una suerte de ferias para la venta de objetos, generalmente artísticos, producidos por las mujeres encarceladas, por lo general abundaban pinturas y grabados, pero también había productos de otras manualidades. Las reuniones se realizaban con mucho cuidado, pero hacia 1978 había cedido el carácter bastante clandestino y muy disciplinado de los primeros años. En Belo Horizonte, pareció que el MFPA había conseguido una mayor irradiación entre los grupos cristianos de izquierda. Las acciones iban en aumento, se habían solidificado las direcciones y no pocos grupos en el nordeste deseaban hacer tareas con las poblaciones rurales. Más allá de la voluntad de Terezinha y de buena parte del grupo dirigente de morigerar los términos del enfrentamiento con la dictadura para garantizar los objetivos, lo cierto es que los organismos de

\footnotetext{
18 "Donde el hombre va inhibe. Vas a una reunión de trabajadores, de estudiantes y hay un grupito de mujeres y si hay hombres las inhibe. Si hay hombres ellos inhiben. Porque la mujer no ha sido entrenada, ella no tiene velocidad mental, porque siempre mandó el hombre. Siempre fue jefe y patrón" (Ibídem).

19 "Ellos querían morder y yo decía "no me vengan a hacer política dentro del Movimiento, porque nunca la hubo" (Ibídem).
} 


\section{Dora Barrancos}

inteligencia estaban vigilantes y no faltaron las calificaciones de "comunista" al MFPA, y de vincularlo estrechamente con las agencias más radicalizadas.

El MFPA estaba organizado en torno de un Directorio central con sede en Sao Paulo que integraba representaciones del interior, pero hacia 1977, en una asamblea se tomó la decisión de que habría autonomía para los directorios locales, tal vez porque había pronunciamientos relacionados con no impedir la participación masculina, y también para un diseño más autónomo de las metodologías de acción, según regiones, que no podría omitir lazos con formaciones políticas. Tal vez hubo desacuerdos desde el inicio con la estrategia del MFPA, más allá de los plegamientos obtenidos, pero lo cierto es que sobre todo en Belo Horizonte aparecieron las fisuras más significativas. Allí, la convocante era la abogada Helena Greco, ${ }^{20}$ que ya tenía 61 años cuando se decidió a militar contra la dictadura y encontró un lugar en el movimiento iniciado por Therezinha. Las tensiones fueron morigeradas pero a menudo las discusiones distanciaban a nuestras mujeres. Grecco ha relatado:

\footnotetext{
"Quando me perguntavam se eu conseguia trabalhar com a Terezinha, eu respondia: "Não, não consigo". Tínhamos modus operandis completamente diferentes, ela era uma pessoa muito interessante, vivia dizendo: "Não adianta querer transformar o Movimento Feminista de Anistia, nós somos da burguesia mesmo, e vamos continuar na burguesia. Não temos nada a ver com o resto da situação." De modo que trabalhávamos com muitos embates". ${ }^{21}$
}

No había dudas de que al inicio, en 1975, el MFPA había sido una referencia para la resistencia, pero había que accionar de un modo más confrontativo. Grecco recordaba:

"Conseguimos formar o primeiro núcleo do movimento, cujo lema era: "A luta pela Anistia Geral e Irrestrita, dentro de uma luta sem tréguas pelos direitos humanos". A Terezinha Zerbini, presidente nacional, dizia que o nosso trabalho era "pela defesa da mulher e para que ela influencie a sociedade". Não era só o que queríamos e, assim, um grupo de mulheres mais batalhadoras se uniu. Começou da maneira que a Terezinha queria, mansa e suave, depois passou a ter muita influência. Em 1975, todo mundo estava calado, todo mundo estava calado mesmo,

\footnotetext{
${ }^{20}$ Helena Grecco nació en Minas Gerais, en 1916 y murió en 2011. Fue militante del Partido dos Trabalhadores (PT) y en 1982 se tornó la primera mujer representante en la Cámara de Vereadores (municipal) de Belo Horizonte.

21 "Cuando me preguntaban si podía trabajar con Therezinha, yo respondía: "No, no con ella". Teníamos modus operandis completamente diferentes. Ella era una persona muy interesante, vivía diciendo: "No se gana nada querer transformar el MFPA, nosotras somos burguesas y vamos a continuar en la burguesía. No tenemos nada que ver con el resto de la situación". De modo que trabajábamos con muchos embates" (Traducción de la autora). Helena Grecco en "A entrevista concedida a $T \& D$, em meados de 94, revela um pouco da trajetória dessa mineira para quem a solidariedade não é só no cáncer", en http://www.teoriaedebate.org.br/materias/nacional/helena-greco?page=full
} 
e nós mulheres levantamos a voz a favor da anistia e dos direitos humanos e contra a discriminação da mulher. Assim formamos os nossos núcleos, foram nove núcleos". ${ }^{22}$

En febrero de 1978, surgió el Comité Brasileiro pela Anistia (CBA) y se trató de una agencia mucho más amplia porque convocó también a organizaciones políticas y sociales y el MFPA participó del nuevo organismo que se extendió por diversos lugares del país. Grecco recuerda:

"Era uma luta muito mais profunda, pela democracia e aí surgiu o Comitê Brasileiro pela Anistia (CBA). Eu fui vice-presidente do CBA em Minas e depois fiquei na Presidência, porque o presidente teve de se afastar por motivos de saúde. Já tínhamos discutido que o Movimento Feminino pela Anistia poderia desaparecer aqui em Minas. Eu já tinha discutido dentro do movimento que estava na hora de realmente engrossar as fileiras do CBA, que todo mundo deveria participar. Gostava de atender à questão da democracia, e o movimento feminino continuaria tratando unicamente a questão da mulher na política". ${ }^{23}$

Como fuere, en 1979, el MFPA comenzó a publicar la revista "Maria Quitéria” seguramente con ánimo de mostrar su lozanía aunque enfrentaba muchos disensos, mientras que el CBA inició la edición de su Boletín, pero más allá de las diferencias de enfoque, énfasis y métodos, ambas organizaciones fueran decisivas en la lucha para la conquista de la amnistía que se consagró por la ley 6683 de agosto de 1979. Se iniciaba el ciclo terminal de la dictadura brasileña, y sin duda hubo una evolución para el MFPA y sus tensiones dando lugar a varios segmentos, pero de modo subrayado fueron los núcleos cuyas sedes principales se hallaban en Río de Janeiro, Fortaleza y Belo Horizonte quienes constituyeron una nueva entidad, el Movimento Femenino pela Anistia e Liberdades Democráticas (MFPALD), y Helena Grecco fue su principal dirigente. Se trataba de proseguir los combates para la reconquista completa de la democracia en Brasil, un jalón que sólo se obtendría en 1985, y las mujeres fueron parte inexorable de esa saga.

\footnotetext{
22 “Conseguimos formar el primer núcleo del movimiento cuyo lema era la lucha por la amnistía general e irrestricta, dentro de una lucha sin tregua por los derechos humanos. Terezinha Zerbini, presidenta nacional, decía que nuestro trabajo era "por la defensa de la mujer y para que ella influenciara a la sociedad". Pero no era eso solo lo que queríamos y así, un grupo de mujeres más trabajadoras se unió. Comenzó del modo en que Terezinha quería, de modo manso y suave, después pasó a tener mucha influencia. En 1975, todo el mundo estaba callado, y nosotras las mujeres levantamos la voz a favor de la amnistía y de los derechos humanos, y contra la discriminación de la mujer. Así formamos nuestros núcleos que fueron nueve”. Ibídem (Traducción de la autora).

23 "Era una lucha mucho más profunda por la democracia y surgió el Comitê Brasileiro pela Anistia (CBA). Fui vice-presidente do CBA en Minas (Gerais) y desoués quedé en la Presidencia, porque el presidente debió separarse por motivos de salud. Ya habíamos discutido que el Movimento Feminino pela Anistia podría desaparecer aqui en Minas (Gerais). Yo había discutido dentro del movimiento que había llegado la hora de realmente ampliar las filas del CBA, y que todo el mundo debería participar. Me gustaba atender la cuestión de la democracia, y el movimiento femenino continuaría tratando unicamente la cuestión de la mujer en la política". Ibídem (Traducción de la autora).
} 


\section{Dora Barrancos}

\section{Conclusiones}

Este artículo se ha centrado en dos países latinoamericanos en un lapso de aproximadamente dos décadas, 1954-1975, momento en que arreciaron las acciones norteamericanas para impedir gobiernos que pudieran significar orientaciones de izquierda. Ese contexto particular de la Guerra fría, abierto a mediados de la década de 1950, tiene decisiva responsabilidad en el ciclo de dictaduras cuyo inicio fue la derrocada del Presidente Arbenz en Guatemala, en donde actuó de manera irrefutable el Departamento de Estado a través de reconocidos mecanismos de la CIA. Un año más tarde, era destituido el Presidente Perón en la Argentina, y aunque en este caso las contribuciones de los Estados Unidos de América resultaron menos directas, no puede decirse lo mismo del periodo pos peronista en que se asistió a una escalada de la Doctrina de la Seguridad Nacional, con claro acatamiento a los objetivos de aquella nación. Casi una década más tarde, se producía el golpe de estado en Brasil ocasionando la caída del Presidente Goulart, y en este caso las circunstancias fueron más próximas a las vividas por Guatemala, pues como en aquel país los sectores de dominio económico y político adujeron que había franco peligro de caída en el comunismo, y en ambas naciones fue destacado el papel de la CIA.

En esos dos escenarios - que ha obligado a una revisión de los respectivos contextos- se rescata a mujeres que sufrieron de diferente modo humillaciones, hostilidades y hasta duras penalidades, como torturas y prisión. En el caso de Guatemala se recorta a María Cristina Vilanova de Arbenz, la esposa del Presidente Jacobo Arbenz, quien fue una figura gravitante en su vida y hasta en las orientaciones transformadoras que imprimió a su gobierno. El asedio que sufrió María revela hasta qué punto hubo ensañamientos con el ciclo de reformas económicas y sociales vividos por Guatemala durante el gobierno de su marido, la impiedosa maledicencia de los detractores que no repararon en cuestiones privadas para justificar la renuncia obligada del marido, y que llevaron al ruedo de los opositores imágenes deformadas de su vida. María sufrió un exilio desventurado, con el suicidio de sus hijas mujeres, y con enormes dificultades para la contención de su esposo quien nunca pudo reponerse de la experiencia del derrocamiento, severo en su propia admonición de no haber resistido la asonada. María ilumina bien los avatares de la Guerra fría sobre ciertas congéneres que fueron blanco de represalias sobre todo morales y estigmatizantes.

Finalmente, se introduce un movimiento femenino en el marco de las luchas contra la dictadura impuesta en Brasil en 1964, con un marcado ascenso autoritario y represor en 1968, ciclo aciago que se fue atenuando algunos años más tarde, cuando vieron la luz movimientos resistentes. Fue ciertamente precursor el Movimento Femenino pela Anistía (MFPA) que vio la luz en 1975 y 
que estuvo en manos de mujeres, realizando un curso singular de aglutinación defensiva ante la dictadura. En efecto, su activismo permitió que muchas mujeres se unieran en la solicitud del cese de las persecuciones y por una amplia amnistía que posibilitara restituir la paz a los hogares y a Brasil. Aunque su empeño fue ciertamente morigerado, pues algunas líderes pensaban que no había que ofuscar a los militares y que lo mejor era conservar una estrategia moderada y muy especialmente exenta de cualquier identificación política o ideológica -por lo que no se permitía que los varones tomaran decisiones en sus reuniones-, su movilización fue un aporte de gran significado para el camino de la redemocratización.

Como se ha visto, las mujeres hostilizadas por los cuadros situacionales de represión durante la Guerra fría en América Latina, pudieron ofrecer resistencia y contribuyeron a las oposiciones, y muy a menudo a la perturbación y al desorden con la misma calidad que sus compañeros varones.

\section{Bibliografia}

Anahté (1996). Entrevista a Maria Vilanova de Arbenz. Crónica, año IX (449)-1996. http://cronica.ufm.edu/index.php/DOC487.pdf.

Ansaldi, W. y Giordano, V. (2012). América Latina. La construcción del orden. T.2, Buenos Aires: Ariel.

Bozza, J. A. (2009). Trabajo silencioso. Agencias anticomunistas en el sindicalismo latinoamericano durante la Guerra Fría. Conflicto Social, Año 2, N² 2, Diciembre 2009. Revista del Programa de Investigaciones sobre Conflicto Social CABA: Instituto de Investigaciones $\begin{array}{llll}\text { Gino Germani/Facultad de Ciencias } & \text { Sociales-UBA, }\end{array}$ http://www.iigg.fsoc.uba.ar/conflictosocial/revista.

Cabrera Geserick, M. (2009). María Vilanova de Arbenz: Un capítulo se cierra. Boletín AFEHC, No. 41, junio de 2009, 123-140.

Dreiffus, R. A. (1981) 1964: A conquista do Estado. Ação Política, Poder e Golpe de Classe, Petropolis: Editorial Vozes.

De Lucena, E. (2012) "Minha história - Therezinha Zerbini: A "burguesona" que foi à luta". Folha de Sao Paulo. 11/07/2012, http://www1.folha.uol.com.br/poder/2012/07/1113275-minhahistoria---therezinha-zerbini-a-burguesona-que-foi-a-luta.shtml

Fico, C. (2008). O grande irmão: da Operação Brother Sam aos anos de chumbo. O governo dos Estados Unidos e a ditadura militar brasileira. Rio de Janeiro: Civilização Brasileira. 


\section{Dora Barrancos}

Fonteles Duarte, A. (2011). Mulheres em guarda contra a repressao. En: Pedro, J. M., Scheibe Wolff, C. y Veiga, A. M., Resistências, Gênero e Feminismos contra as ditaduras no Cone Sul. Santa Catarina: Editorial Mulheres.

García Ferreira, R. (2009). A propósito de María Vilanova de Arbenz. Boletín AFEHC, No. 42, octubre 2009, s/n/p.

García Ferreira, R. (2006). La CIA y el exilio de Jacobo Arbenz. Perfiles Latinoamericanos, No 28- 2006 , 60-82. http://www1.folha.uol.com.br/poder/2012/07/1113275-minha-historia--therezinha-zerbini-a-burguesona-que-foi-a-luta.shtml

Hunt, H. (1975). Memorias de un espía. De la C IA al escándalo Watergate. Barcelona: Noguer.

Morgenfeld, L. (2010). El inicio de la Guerra fría y el sistema interamericano. Argntina frente a Estados Unidos en la Conferencia de Caracas. Contemporanea. Historia y problemas del siglo $X X$, Vol. 1, Año 1, 2010, 75-97.

Pedro, J. M., Scheibe Wolff, C. y Veiga, A. M. (2011). Resistências, Gênero e Feminismos contra as ditaduras no Cone Sul. Santa Catarina: Editorial Mulheres.

Pellecer, C. M. (1997). Arbenz y yo. Guatemala: Artemis.

Ramírez, H. (2012). El golpe de Estado de 1964 en Brasil desde una perspectiva socio-política. PolHis , Año 5, № 9 (2012), 255- 265.

Stonor Saunders, F. (1999). La CIA y la guerra fría cultural. Madrid: Debate.

Vilanova de Arbenz, M. C. (2003). Mi esposo, el Presidente Arbenz. Guatemala: Editorial Universitaria.

Recepción: 22/08/2021

Evaluado: $18 / 11 / 2021$

Versión Final: 15/12/2021 